\title{
Existence and uniqueness of positive periodic solution for $\phi$-Laplacian Liénard equation
}

\section{Yun $\mathrm{Xin}^{1 *}$, Xuefeng $\mathrm{Han}^{2}$ and Zhibo Cheng ${ }^{2}$}

\section{"Correspondence:} xy_1982@126.com

${ }^{1}$ College of Computer Science and Technology, Henan Polytechnic University, Jiaozuo, 454000, China Full list of author information is available at the end of the article

\begin{abstract}
By applying the Manásevich-Mawhin continuation theorem, we establish some sufficient conditions for the existence and uniqueness of positive periodic solutions for the Liénard type $\phi$-Laplacian operator equation.
\end{abstract}

MSC: $34 \mathrm{~K} 13 ; 34 \mathrm{C} 25$

Keywords: positive periodic solution; $\phi$-Laplacian; uniqueness; Liénard equation

\section{Introduction}

Consider the following Liénard equation:

$$
\left(\phi\left(x^{\prime}(t)\right)\right)^{\prime}+f(t, x(t)) x^{\prime}(t)+g(t, x(t))=e(t)
$$

$f, g \in \operatorname{Car}(\mathbb{R} \times \mathbb{R}, \mathbb{R})$ are the $L^{2}$-Carathéodory functions, which means that they are measurable in the first variable and continuous in the second variable, and for every $0<r<s$ there exists $h_{r, s} \in L^{2}[0, T]$ such that $|g(t, x(t))| \leq h_{r, s}$ for all $x \in[r, s]$ and a.e. $t \in[0, T]$; and $f, g$ are the $T$-periodic functions about $t . e \in L^{2}([0, T], \mathbb{R})$ is $T$-periodic.

Here let $\phi: \mathbb{R} \rightarrow \mathbb{R}$ be a continuous function and $\phi(0)=0$ which satisfies:

$\left(\mathrm{A}_{1}\right)\left(\phi\left(x_{1}\right)-\phi\left(x_{2}\right)\right)\left(x_{1}-x_{2}\right)>0, \forall x_{1} \neq x_{2}, x_{1}, x_{2} \in \mathbb{R}$.

$\left(\mathrm{A}_{2}\right)$ There exists a function $\alpha:[0,+\infty] \rightarrow[0,+\infty], \alpha(s) \rightarrow+\infty$ as $s \rightarrow+\infty$, such that $\phi(x) \cdot x \geq \alpha(|x|)|x|, \forall x \in \mathbb{R}$.

It is easy to see that $\phi$ represents a large class of nonlinear operators, including $\phi_{p}: \mathbb{R} \rightarrow$ $\mathbb{R}$ which is a $p$-Laplacian, i.e., $\phi_{p}(x)=|x|^{p-2} x$ for $x \in \mathbb{R}$.

As is well known, the existence of periodic solutions for a $p$-Laplacian differential equation was extensively studied (see [1-7] and the references therein). In recent years, there also appeared some results on the $\phi$-Laplacian differential equation; see [8-10]. In [8], Ding et al. investigate the existence of periodic solutions for the Liénard type $\phi$-Laplacian differential equation (1.1) with the following assumption:

$\left(\mathrm{H}_{0}\right) f(t, u)=f(u)$, and $g(t, u)=g(u)$, for all $t, u \in \mathbb{R}$.

However, for the existence of periodic solutions to $(1.1)$ without $\left(\mathrm{H}_{0}\right)$, the results are scarce. Thus, it is worthwhile to study (1.1) in this case.

(0) 2014 Xin et al:; licensee Springer. This is an Open Access article distributed under the terms of the Creative Commons Attribution License (http://creativecommons.org/licenses/by/4.0), which permits unrestricted use, distribution, and reproduction in any medium, provided the original work is properly credited. 
In this paper, by using some analysis techniques, we establish some sufficient condition for the existence and uniqueness of positive $T$-periodic solutions of (1.1). The results of this paper complement the results previously found in [8].

\section{Main results}

For convenience, define

$$
C_{T}^{1}=\left\{x \in C^{1}(\mathbb{R}, \mathbb{R}): x \text { is } T \text {-periodic }\right\},
$$

which is a Banach space endowed with the norm $\|\cdot\|$ defined by $\|x\|=\max \left\{|x|_{0},\left|x^{\prime}\right|_{0}\right\}$, for all $x$, and

$$
|x|_{0}=\max _{t \in[0, T]}|x(t)|, \quad\left|x^{\prime}\right|_{0}=\max _{t \in[0, T]}\left|x^{\prime}(t)\right|
$$

For the $T$-periodic boundary value problem

$$
\left(\phi\left(x^{\prime}(t)\right)\right)^{\prime}=\tilde{f}\left(t, x, x^{\prime}\right)
$$

$\phi$ is defined as above and $\tilde{f}:[0, T] \times \mathbb{R} \times \mathbb{R} \rightarrow \mathbb{R}$ is assumed to be Carathéodory.

Lemma 2.1 (Manásevich-Mawhin [11]) Let $\Omega$ be an open bounded set in $C_{T}^{1}$. If

(i) for each $\lambda \in(0,1)$ the problem

$$
\left(\phi\left(x^{\prime}\right)\right)^{\prime}=\lambda \tilde{f}\left(t, x, x^{\prime}\right), \quad x(0)=x(T), \quad x^{\prime}(0)=x^{\prime}(T)
$$

has no solution on $\partial \Omega$;

(ii) the equation

$$
F(a):=\frac{1}{T} \int_{0}^{T} \tilde{f}\left(t, x, x^{\prime}\right) d t=0
$$

has no solution on $\partial \Omega \cap \mathbb{R}$;

(iii) the Brouwer degree of $F$ is

$$
\operatorname{deg}\{F, \Omega \cap \mathbb{R}, 0\} \neq 0,
$$

then the periodic boundary value problem (2.1) has at least one periodic solution on $\bar{\Omega}$.

Lemma 2.2 If $\phi(x)$ is bounded, then $x$ is also bounded.

Proof Since $\phi(x)$ is bounded, there exists a positive constant $N$ such that $|\phi(x)| \leq N$. From $\left(\mathrm{A}_{2}\right)$, we have $\alpha(|x|)|x| \leq \phi(x) \cdot x \leq|\phi(x)| \cdot|x| \leq N|x|$. Hence, we can get $\alpha(|x|) \leq N$ for all $x \in \mathbb{R}$. If $x$ is not bounded, then from the definition of $\alpha$, we get $\alpha(|x|)>N$ for some $x \in \mathbb{R}$, which is a contradiction. So $x$ is also bounded.

For the sake of convenience, we list the following assumptions which will be used repeatedly in the sequel: 
$\left(\mathrm{H}_{1}\right)$ There exists a positive constant $D$ such that $g(t, x)-e(t)<0$ for $x>D$ and $t \in \mathbb{R}$, $g(t, x)-e(t)>0$ for $x \leq 0$ and $t \in \mathbb{R}$.

$\left(\mathrm{H}_{2}\right)$ There exists a constant $\sigma>0$ such that $\inf _{(t, u) \in[0, T] \times \mathbb{R}}|f(t, u)| \geq \sigma>0$.

$\left(\mathrm{H}_{3}\right)$ There exist positive constants $a, b, B$ such that

$$
|g(t, x)| \leq a \cdot|x|+b, \quad \text { for }|x| \geq B \text { and } t \in \mathbb{R} .
$$

$\left(\mathrm{H}_{4}\right) g$ is a continuous differentiable function defined on $\mathbb{R}$, and $g_{x}(t, x)<0$, where $g_{x}(t, x)=$ $\frac{\partial g(t, x)}{\partial x}$.

Applying Lemmas 2.1-2.2, we obtain the following.

Theorem 2.1 Assume that $\left(\mathrm{H}_{1}\right)-\left(\mathrm{H}_{3}\right)$ hold. Then (1.1) has positive T-periodic solution if $\sigma-\frac{a T}{2}>0$.

Proof Consider the homotopic equation of (1.1) as follows:

$$
\left(\phi\left(x^{\prime}(t)\right)\right)^{\prime}+\lambda f(t, x(t)) x^{\prime}(t)+\lambda g(t, x(t))=\lambda e(t)
$$

Firstly, we will claim that the set of all possible $T$-periodic solutions of (2.2) is bounded. Let $x(t) \in C_{T}^{1}$ be an arbitrary solution of (2.2) with period $T$. As $x(0)=x(T)$, there exists $t_{0} \in[0, T]$ such that $x^{\prime}\left(t_{0}\right)=0$, while $\phi(0)=0$, and we see

$$
\begin{aligned}
\left|\phi\left(x^{\prime}(t)\right)\right| & =\left|\int_{t_{0}}^{t}\left(\phi\left(x^{\prime}(s)\right)\right)^{\prime} d s\right| \\
& \leq \lambda \int_{0}^{T}|f(t, x(t))|\left|x^{\prime}(t)\right| d t+\lambda \int_{0}^{T}|g(t, x(t))| d t+\lambda \int_{0}^{T}|e(t)| d t,
\end{aligned}
$$

where $t \in\left[t_{0}, t_{0}+T\right]$.

Consider the equivalent system of (2.2)

$$
\left\{\begin{array}{l}
\phi\left(x^{\prime}(t)\right)=z(t), \\
z^{\prime}(t)=-\lambda f(t, x(t)) x^{\prime}(t)-\lambda g(t, x(t))+\lambda e(t) .
\end{array}\right.
$$

We first claim that there is a constant $\xi \in \mathbb{R}$ such that

$$
|x(\xi)| \leq D
$$

In view of $\int_{0}^{T} x^{\prime}(t) d t=0$, we know that there exist two constants $t_{1}, t_{2} \in[0, T]$ such that

$$
x^{\prime}\left(t_{1}\right) \geq 0, \quad x^{\prime}\left(t_{2}\right) \leq 0 .
$$

From the first equation of (2.4) and $\left(\mathrm{A}_{2}\right)$, we know

$$
\begin{aligned}
& z\left(t_{1}\right)=\phi\left(x^{\prime}\left(t_{1}\right)\right) \geq 0, \\
& z\left(t_{2}\right)=\phi\left(x^{\prime}\left(t_{2}\right)\right) \leq 0 .
\end{aligned}
$$


Let $t_{3}, t_{4} \in[0, T]$ be, respectively, a global maximum and minimum point of $z(t)$; clearly, we have

$$
\begin{aligned}
& z\left(t_{3}\right) \geq 0, \quad z^{\prime}\left(t_{3}\right)=0 ; \\
& z\left(t_{4}\right) \leq 0, \quad z^{\prime}\left(t_{4}\right)=0 .
\end{aligned}
$$

From $\left(\mathrm{H}_{2}\right)$ we know $f$ will not change sign for $(t, x) \in[0, T] \times \mathbb{R}$. Without loss of generality, suppose $f(t, x)>0$ for $(t, x) \in[0, T] \times \mathbb{R}$ and upon substitution of (2.6) into the second equation of (2.4), we have

$$
-\lambda g\left(t_{3}, x\left(t_{3}\right)\right)+\lambda e\left(t_{3}\right)=\lambda f\left(t_{3}, x\left(t_{3}\right)\right) x^{\prime}\left(t_{3}\right) .
$$

Since $z\left(t_{3}\right)=\phi\left(x^{\prime}\left(t_{3}\right)\right) \geq 0$, from $\left(\mathrm{A}_{2}\right)$, we know that $x^{\prime}\left(t_{3}\right) \geq 0$. So, we have

$$
-g\left(t_{3}, x\left(t_{3}\right)\right)+e\left(t_{3}\right)=f\left(t_{3}, x\left(t_{3}\right)\right) x^{\prime}\left(t_{3}\right) \geq 0,
$$

i.e.

$$
g\left(t_{3}, x\left(t_{3}\right)\right)-e\left(t_{3}\right) \leq 0 \text {. }
$$

From $\left(\mathrm{H}_{1}\right)$, we know that

$$
x\left(t_{3}\right)>0 .
$$

Similarly, from (2.7) we have

$$
g\left(t_{4}, x\left(t_{4}\right)\right)-e\left(t_{4}\right) \geq 0
$$

and again by $\left(\mathrm{H}_{1}\right)$

$$
x\left(t_{4}\right) \leq D .
$$

Case (1): If $x\left(t_{3}\right) \in(0, D)$, define $\xi=t_{3}$, obviously, $|x(\xi)| \leq D$.

Case (2): If $x\left(t_{3}\right)>D$, from (2.8) and the fact that $x(t)$ is a continuous function in $\mathbb{R}$, there exists a constant $\xi$ between $x\left(t_{3}\right)$ and $x\left(t_{4}\right)$ such that $|x(\xi)|=D$. This proves (2.5).

Then we have

$$
|x(t)|=\left|x(\xi)+\int_{\xi}^{t} x^{\prime}(s) d s\right| \leq D+\int_{\xi}^{t}\left|x^{\prime}(s)\right| d s, \quad t \in[\xi, \xi+T]
$$

and

$$
\begin{aligned}
|x(t)| & =|x(t-T)|=\left|x(\xi)-\int_{t-T}^{\xi} x^{\prime}(s) d s\right| \\
& \leq D+\int_{t-T}^{\xi}\left|x^{\prime}(s)\right| d s, \quad t \in[\xi, \xi+T] .
\end{aligned}
$$


Combining the above two inequalities, we obtain

$$
\begin{aligned}
|x|_{0} & =\max _{t \in[0, T]}|x(t)|=\max _{t \in[\xi, \xi+T]}|x(t)| \\
& \leq \max _{t \in[\xi, \xi+T]}\left\{D+\frac{1}{2}\left(\int_{\xi}^{t}\left|x^{\prime}(s)\right| d s+\int_{t-T}^{\xi}\left|x^{\prime}(s)\right| d s\right)\right\} \\
& \leq D+\frac{1}{2} \int_{0}^{T}\left|x^{\prime}(s)\right| d s .
\end{aligned}
$$

Since $x^{\prime}(t)$ is $T$-periodic, multiplying $x^{\prime}(t)$ and (2.2) and then integrating it from 0 to $T$, we have

$$
\begin{aligned}
0 & =\int_{0}^{T}\left(\phi\left(x^{\prime}(t)\right)\right)^{\prime} x^{\prime}(t) d t \\
& =-\lambda \int_{0}^{T} f(t, x(t))\left|x^{\prime}(t)\right|^{2} d t-\lambda \int_{0}^{T} g(t, x(t)) x^{\prime}(t) d t+\lambda \int_{0}^{T} e(t) x^{\prime}(t) d t .
\end{aligned}
$$

In view of (2.10), we have

$$
\left.\left|\int_{0}^{T} f(t, x(t))\right| x^{\prime}(t)\right|^{2} d t|=|-\int_{0}^{T} g(t, x(t)) x^{\prime}(t) d t+\int_{0}^{T} e(t) x^{\prime}(t) d t \mid .
$$

From $\left(\mathrm{H}_{2}\right)$, we know

$$
\left.\left.\left|\int_{0}^{T} f(t, x(t))\right| x^{\prime}(t)\right|^{2} d t\left|=\int_{0}^{T}\right| f(t, x(t))|| x^{\prime}(t)\right|^{2} d t \geq \sigma \int_{0}^{T}\left|x^{\prime}(t)\right|^{2} d t .
$$

Set

$$
E_{1}=\{t \in[0, T]|| x(t) \mid \leq B\}, \quad E_{2}=\{t \in[0, T]|| x(t) \mid \geq B\} .
$$

From $\left(\mathrm{H}_{3}\right)$, we have

$$
\begin{aligned}
\sigma \int_{0}^{T}\left|x^{\prime}(t)\right|^{2} d t \leq & \int_{E_{1}+E_{2}}|g(t, x(t))|\left|x^{\prime}(t)\right| d t+\int_{0}^{T}|e(t)|\left|x^{\prime}(t)\right| d t \\
\leq & \left(\int_{E_{1}}|g(t, x(t))|^{2} d t\right)^{\frac{1}{2}}\left(\int_{0}^{T}\left|x^{\prime}(t)\right|^{2} d t\right)^{\frac{1}{2}}+a \int_{0}^{T}|x(t)|\left|x^{\prime}(t)\right| d t \\
& +b \int_{0}^{T}\left|x^{\prime}(t)\right| d t+\int_{0}^{T}|e(t)|\left|x^{\prime}(t)\right| d t \\
\leq & \left|g_{B}\right|_{2}\left(\int_{0}^{T}\left|x^{\prime}(t)\right|^{2} d t\right)^{\frac{1}{2}}+a\left(D+\frac{1}{2} \int_{0}^{T}\left|x^{\prime}(t)\right| d t\right) \int_{0}^{T}\left|x^{\prime}(t)\right| d t \\
& +b T^{\frac{1}{2}}\left(\int_{0}^{T}\left|x^{\prime}(t)\right|^{2} d t\right)^{\frac{1}{2}}+\left(\int_{0}^{T}|e(t)|^{2} d t\right)^{\frac{1}{2}}\left(\int_{0}^{T}\left|x^{\prime}(t)\right|^{2} d t\right)^{\frac{1}{2}} \\
\leq & \frac{a T}{2} \int_{0}^{T}\left|x^{\prime}(t)\right|^{2} d t+\left(a D T^{\frac{1}{2}}+b T^{\frac{1}{2}}+\left|g_{B}\right|_{2}+|e|_{2}\right) \\
& \times\left(\int_{0}^{T}\left|x^{\prime}(t)\right|^{2} d t\right)^{\frac{1}{2}},
\end{aligned}
$$

where $g_{B}=\max _{|x| \leq B}|g(t, x(t))|,\left|g_{B}\right|_{2}=\left(\int_{0}^{T}\left|g_{B}\right|^{2} d t\right)^{\frac{1}{2}}$. 
Since $\sigma-\frac{a T}{2}>0$, it is easy to see that there is a constant $M_{1}^{\prime}>0$ (independent of $\lambda$ ) such that

$$
\int_{0}^{T}\left|x^{\prime}(t)\right|^{2} d t \leq M_{1}^{\prime}
$$

By applying Hölder's inequality and (2.9), we have

$$
|x|_{0} \leq D+\frac{1}{2} \int_{0}^{T}\left|x^{\prime}(s)\right| d s \leq D+\frac{1}{2} T^{\frac{1}{2}}\left(\int_{0}^{T}\left|x^{\prime}(s)\right|^{2} d s\right)^{\frac{1}{2}} \leq D+\frac{1}{2} T^{\frac{1}{2}}\left(M_{1}^{\prime}\right)^{\frac{1}{2}}:=M_{1} .
$$

In view of (2.3), we have

$$
\begin{aligned}
\left|\phi\left(x^{\prime}\right)\right|_{0}= & \max _{t \in[0, T]}\left\{\left|\phi\left(x^{\prime}(t)\right)\right|\right\} \\
= & \max _{t \in\left[t_{0}, t_{0}+T\right]}\left\{\left|\int_{t_{0}}^{t}\left(\phi\left(x^{\prime}(s)\right)\right)^{\prime} d s\right|\right\} \\
\leq & \int_{0}^{T}|f(t, x(t))|\left|x^{\prime}(t)\right| d t+\int_{0}^{T}|g(t, x(t))| d t+\int_{0}^{T}|e(t)| d t \\
\leq & \left(\int_{0}^{T}|f(t, x(t))|^{2} d t\right)^{\frac{1}{2}}\left(\int_{0}^{T}\left|x^{\prime}(t)\right|^{2} d t\right)^{\frac{1}{2}} \\
& +T^{\frac{1}{2}}\left(\int_{0}^{T}|g(t, x(t))|^{2} d t\right)^{\frac{1}{2}}+T^{\frac{1}{2}}\left(\int_{0}^{T}|e(t)|^{2} d t\right)^{\frac{1}{2}} \\
\leq & \left|f_{M_{1}}\right|_{2}\left(M_{1}^{\prime}\right)^{\frac{1}{2}}+T^{\frac{1}{2}}\left|g_{M_{1}}\right|_{2}+T^{\frac{1}{2}}|e|_{2}:=M_{2}^{\prime},
\end{aligned}
$$

where $\left|f_{M_{1}}\right|=\max _{|x(t)| \leq M_{1}}|f(t, x(t))|$.

Thus, from Lemma 2.2, we know that there exists some positive constant $M_{2}$ such that, for all $t \in \mathbb{R}$,

$$
\left|x^{\prime}(t)\right| \leq M_{2}
$$

Set $M=\sqrt{M_{1}^{2}+M_{2}^{2}}+1$; we have

$$
\Omega=\left\{\left.x \in C_{T}^{1}(\mathbb{R}, \mathbb{R})|| x\right|_{0} \leq M+1,\left|x^{\prime}\right|_{0} \leq M+1\right\}
$$

and we know that (2.2) has no solution on $\partial \Omega$ as $\lambda \in(0,1)$ and when $x(t) \in \partial \Omega \cap \mathbb{R}, x(t)=$ $M+1$ or $x(t)=-M-1$, from (2.9) we know that $M+1>D$. So, from $\left(\mathrm{H}_{1}\right)$ we see that

$$
\begin{aligned}
& \frac{1}{T} \int_{0}^{T}\{g(t, M+1)-e(t)\} d t<0, \\
& \frac{1}{T} \int_{0}^{T}\{g(t,-M-1)-e(t)\} d t>0 .
\end{aligned}
$$

So condition (ii) is also satisfied. Set

$$
H(x, \mu)=\mu x-(1-\mu) \frac{1}{T} \int_{0}^{T}\{g(t, x)-e(t)\} d t
$$


where $x \in \partial \Omega \cap \mathbb{R}, \mu \in[0,1]$, and we have

$$
x H(x, \mu)=\mu x^{2}-(1-\mu) x \frac{1}{T} \int_{0}^{T}\{g(t, x)-e(t)\} d t>0
$$

and thus $H(x, \mu)$ is a homotopic transformation and

$$
\begin{aligned}
\operatorname{deg}\{F, \Omega \cap \mathbb{R}, 0\} & =\operatorname{deg}\left\{-\frac{1}{T} \int_{0}^{T}\{g(t, x)-e(t)\} d t, \Omega \cap \mathbb{R}, 0\right\} \\
& =\operatorname{deg}\{x, \Omega \cap \mathbb{R}, 0\} \neq 0 .
\end{aligned}
$$

So condition (iii) is satisfied. In view of Lemma (2.1), there exists a solution with period $T$.

Suppose that $x(t)$ is the $T$-periodic solution of (1.1). Let $\bar{t}$ be the global minimum point of $x(t)$ on $[0, T]$. Then $x^{\prime}(\bar{t})=0$ and we claim that

$$
\left(\phi\left(x^{\prime}(\bar{t})\right)\right)^{\prime} \geq 0
$$

If not, i.e., $\left(\phi\left(x^{\prime}(\bar{t})\right)\right)^{\prime}<0$, then there exists $\varepsilon>0$ such that $\left(\phi\left(x^{\prime}(t)\right)\right)^{\prime}<0$ for $t \in(\bar{t}-\varepsilon, \bar{t}+\varepsilon)$. Therefore, $\phi\left(x^{\prime}(t)\right)$ is strictly decreasing for $t \in(\bar{t}-\varepsilon, \bar{t}+\varepsilon)$. From $\left(\mathrm{A}_{1}\right)$, we know that $x^{\prime}(t)$ is strictly decreasing for $t \in(\bar{t}-\varepsilon, \bar{t}+\varepsilon)$. This contradicts the definition of $\bar{t}$. Thus, (2.12) is true. From (1.1) and (2.12), we have

$$
g(\bar{t}, x(\bar{t}))-e(\bar{t}) \leq 0
$$

In view of $\left(\mathrm{H}_{1}\right),(2.13)$ implies $x(\bar{t})>0$. Thus,

$$
x(t) \geq \min _{t \in[0, T]} x(t)=x(\bar{t})>0, \quad \text { for all } t \in \mathbb{R},
$$

which implies that (1.1) has at least one positive solution with period $T$. This completes the proof.

Next, we consider $f(t, x(t)) \equiv f(x(t))$, then (1.1) is transformed into

$$
\left(\phi\left(x^{\prime}(t)\right)\right)^{\prime}+f(x(t)) x^{\prime}(t)+g(t, x(t))=e(t) .
$$

Set

$$
F(x)=\int_{0}^{x} f(u) d u, \quad \phi\left(x^{\prime}(t)\right)=y(t)-F(x(t)),
$$

and we can rewrite (2.14) in the following form:

$$
\left\{\begin{array}{l}
\phi\left(x^{\prime}(t)\right)=y(t)-F(x(t)), \\
y^{\prime}(t)=-g(t, x(t))+e(t) .
\end{array}\right.
$$

Lemma 2.3 If $\left(\mathrm{H}_{4}\right)$ holds, then (2.14) has at most one T-periodic solution in $C_{T}^{1}$. 
Proof Assume that $x_{1}(t)$ and $x_{2}(t)$ are two $T$-periodic solutions of (2.14). Then we obtain

$$
\left\{\begin{array}{l}
\phi\left(x_{i}^{\prime}(t)\right)=y_{i}(t)-F\left(x_{i}(t)\right) \\
y_{i}^{\prime}(t)=-g\left(t, x_{i}(t)\right)+e(t), \quad i=1,2 .
\end{array}\right.
$$

Set

$$
v(t)=x_{1}(t)-x_{2}(t), \quad u(t)=y_{1}(t)-y_{2}(t) .
$$

It follows from (2.16) that

$$
\left\{\begin{array}{l}
\phi\left(x_{1}^{\prime}(t)\right)-\phi\left(x_{2}^{\prime}(t)\right)=u(t)-\left[F\left(x_{1}(t)\right)-F\left(x_{2}(t)\right)\right] \\
u^{\prime}(t)=-\left[g\left(t, x_{1}(t)\right)-g\left(t, x_{2}(t)\right)\right]
\end{array}\right.
$$

Now, we prove that

$$
u(t) \leq 0, \quad \text { for all } t \in \mathbb{R}
$$

In contrast, in view of $x_{1}, x_{2} \in C^{1}[0, T]$, for $t \in \mathbb{R}$, we obtain

$$
\max _{t \in \mathbb{R}} u(t)>0
$$

Then there must exist $t^{*} \in \mathbb{R}$ (for convenience, we can choose $t^{*} \in(0, T)$ ) such that

$$
u\left(t^{*}\right)=\max _{t \in[0, T]} u(t)=\max _{t \in \mathbb{R}} u(t)>0 .
$$

We claim that $u^{\prime \prime}\left(t^{*}\right) \leq 0$. In contrast, we obtain $u^{\prime \prime}\left(t^{*}\right)>0$ and there exists a constant $\varepsilon>0$ such that $u^{\prime \prime}(t)>0$ for $t \in\left(t^{*}-\varepsilon, t^{*}\right]$. Therefore, $u^{\prime}(t)$ is strictly increasing for $t \in\left(t^{*}-\varepsilon, t^{*}\right]$, which implies that

$$
u^{\prime}(t)<u^{\prime}\left(t^{*}\right)=0, \quad \text { for all } t \in\left(t^{*}-\varepsilon, t^{*}\right) .
$$

This contradicts the definition of $t^{*}$. Thus, we get $u^{\prime \prime}\left(t^{*}\right) \leq 0$.

This implies that

$$
\left\{\begin{aligned}
u^{\prime}\left(t^{*}\right) & =-\left[g\left(t^{*}, x_{1}\left(t^{*}\right)\right)-g\left(t^{*}, x_{2}\left(t^{*}\right)\right)\right]=0, \\
u^{\prime \prime}\left(t^{*}\right) & =\left.\left(-\left(g\left(t, x_{1}(t)\right)-g\left(t, x_{2}(t)\right)\right)\right)^{\prime}\right|_{t=t^{*}} \\
& =-\left[\left(\frac{\partial g\left(t^{*}, x_{1}\left(t^{*}\right)\right)}{\partial t}-\frac{\partial g\left(t^{*}, x_{2}\left(t^{*}\right)\right)}{\partial t}\right)+\left(\frac{\partial g\left(t^{*}, x_{1}\left(t^{*}\right)\right)}{\partial x} x_{1}^{\prime}\left(t^{*}\right)-\frac{\partial g\left(t^{*}, x_{2}\left(t^{*}\right)\right)}{\partial x} x_{2}^{\prime}\left(t^{*}\right)\right)\right] \leq 0 .
\end{aligned}\right.
$$

Since $g_{x}(t, x)<0$, from (2.17) and the first equation of (2.18), we get $x_{1}\left(t^{*}\right)=x_{2}\left(t^{*}\right)$. Then, from the second equation of (2.18), we have

$$
\begin{aligned}
u^{\prime \prime}\left(t^{*}\right) & =-\left(g_{x}\left(t^{*}, x_{1}\left(t^{*}\right)\right) x_{1}^{\prime}\left(t^{*}\right)-g_{x}\left(t^{*}, x_{2}\left(t^{*}\right)\right) x_{1}^{\prime}\left(t^{*}\right)\right) \\
& =-g_{x}\left(t^{*}, x_{1}\left(t^{*}\right)\right)\left[x_{1}^{\prime}\left(t^{*}\right)-x_{2}^{\prime}\left(t^{*}\right)\right] \leq 0 .
\end{aligned}
$$


In view of $-g_{x}\left(t^{*}, x_{1}\left(t^{*}\right)\right)>0, u\left(t^{*}\right)=y_{1}\left(t^{*}\right)-y_{2}\left(t^{*}\right)>0$, it follows from (2.19) that

$$
x_{1}^{\prime}\left(t^{*}\right)-x_{2}^{\prime}\left(t^{*}\right) \leq 0
$$

From $\left(A_{1}\right)$, we can see that

$$
\phi\left(x_{1}^{\prime}\left(t^{*}\right)\right)-\phi\left(x_{2}^{\prime}\left(t^{*}\right)\right) \leq 0 \text {. }
$$

From the first equation of (2.17), we know

$$
\begin{aligned}
\phi\left(x_{1}^{\prime}\left(t^{*}\right)\right)-\phi\left(x_{2}^{\prime}\left(t^{*}\right)\right) & =u\left(t^{*}\right)-\left[F\left(x_{1}\left(t^{*}\right)\right)-F\left(x_{2}\left(t^{*}\right)\right)\right] \\
& =u\left(t^{*}\right)-\left[F\left(x_{1}\left(t^{*}\right)\right)-F\left(x_{1}\left(t^{*}\right)\right)\right] \\
& =u\left(t^{*}\right)>0
\end{aligned}
$$

which contradicts (2.20). This contradiction implies that

$$
u(t)=y_{1}(t)-y_{2}(t) \leq 0, \quad \text { for all } t \in \mathbb{R} .
$$

By using a similar argument, we can also show that

$$
y_{2}(t)-y_{1}(t) \leq 0
$$

Therefore, we obtain

$$
y_{1}(t) \equiv y_{2}(t), \quad \text { for all } t \in \mathbb{R} \text {. }
$$

Then, from (2.17), we get

$$
g\left(t, x_{1}(t)\right)-g\left(t, x_{2}(t)\right) \equiv 0, \quad \text { for all } t \in \mathbb{R} .
$$

Again, from $g_{x}(t, x)<0$, we find

$$
x_{1}(t) \equiv x_{2}(t), \quad \text { for all } t \in \mathbb{R} \text {. }
$$

Hence, (2.14) has at most one $T$-periodic solution in $C_{T}^{1}$. The proof of Lemma 2.3 is now complete.

By Lemma 2.3 and Theorem 2.1, we get the following.

Theorem 2.2 Assume $\left(\mathrm{H}_{1}\right)-\left(\mathrm{H}_{4}\right)$ hold. Then (2.14) has a unique positive T-periodic solution if $\sigma-\frac{\alpha T}{2}>0$.

We illustrate our results with some examples.

Example 2.1 Consider the following second-order $p$-Laplacian Liénard equation:

$$
\left(\phi_{p}\left(x^{\prime}(t)\right)\right)^{\prime}+\left(x^{2}(t) \sin ^{2} t+10\right) x^{\prime}(t)-\left(5 x(t)+\sin ^{2} t-8\right)=e^{\cos ^{2} t}
$$

where $\phi_{p}(u)=|u|^{p-2} u$. 
Comparing (2.21) to (1.1), we see that $g(t, x)=-5 x(t)-\sin ^{2} t+8, f(t, x)=x^{2}(t) \sin ^{2} t+10$, $e(t)=e^{\cos ^{2} t}, T=\pi$. Obviously, we know $\phi_{p}$ is an homeomorphism for $\mathbb{R}$ to $\mathbb{R}$, satisfying $\left(\mathrm{A}_{1}\right)$ and $\left(\mathrm{A}_{2}\right)$. Moreover, it is easily seen that there exists a constant $D=3$ such that $\left(\mathrm{H}_{1}\right)$ holds. We have $|f(t, x)|=\left|x^{2}(t) \sin ^{2} t+10\right| \geq 10=\sigma$, then $\left(\mathrm{H}_{2}\right)$ holds. Choose $B>0$; we have $|g(t, x)| \leq 5|x|+9$, here $a=5, b=9$, then $\left(\mathrm{H}_{3}\right)$ holds and $\sigma-\frac{a T}{2}=10-\frac{5 \pi}{2}>0$. So, by Theorem 2.1, we find that (2.21) has a positive periodic solution.

Example 2.2 Consider the following second-order $\phi$-Laplacian Liénard equation:

$$
\left(\phi\left(x^{\prime}(t)\right)\right)^{\prime}-\left(10 x^{4}(t)+200\right) x^{\prime}(t)-\left(100 x(t)+10 \cos ^{2}(t)-15\right)=e^{\sin ^{2} t},
$$

where $\phi(u)=u e^{|u|^{2}}$.

Comparing (2.22) to (2.14), we see that $g(t, x)=-100 x-10 \cos ^{2} t+15, f(x)=-\left(10 x^{4}(t)+\right.$ 200), $e(t)=e^{\sin ^{2} t}, T=\pi$. Obviously, we get

$$
\left(x e^{|x|^{2}}-y e^{|y|^{2}}\right)(x-y) \geq\left(|x| e^{|x|^{2}}-|y| e^{|y|^{2}}\right)(|x|-|y|) \geq 0
$$

and

$$
\phi(x) \cdot x=|x|^{2} e^{|x|^{2}} .
$$

So, we know $\left(\mathrm{A}_{1}\right)$ and $\left(\mathrm{A}_{2}\right)$ hold. We know that $g_{x}(t, x)=-100<0$; then $\left(\mathrm{H}_{4}\right)$ holds. Moreover, it is easily seen that there exists a $D=1$ such that $\left(\mathrm{H}_{1}\right)$ holds. We have $|f(x)|=$ $\left|-\left(10 x^{4}(t)+200\right)\right| \geq 200=\sigma$, then $\left(\mathrm{H}_{2}\right)$ holds. Choose $B>0$; we have $|g(t, x)| \leq 100|x|+25$, here $a=100, b=25$, then $\left(\mathrm{H}_{3}\right)$ holds and $\sigma-\frac{a T}{2}=200-50 \pi>0$. Therefore, by Theorem 2.2, we know that (2.22) has a unique positive periodic solution.

\section{Competing interests}

The authors declare that they have no competing interests.

Authors' contributions

$\mathrm{YX}, \mathrm{XH}$, and ZC worked together in the derivation of the mathematical results. All authors read and approved the final manuscript.

\section{Author details}

${ }^{1}$ College of Computer Science and Technology, Henan Polytechnic University, Jiaozuo, 454000, China. ${ }^{2}$ School of Mathematics and Information Science, Henan Polytechnic University, Jiaozuo, 454000, China.

\section{Acknowledgements}

YX, XH, and ZC would like to thank the referee for invaluable comments and insightful suggestions. This work was supported by NSFC project (Nos. 11326124, 11271339) and Education Department of Henan Province project (No. 14A110002).

Received: 25 August 2014 Accepted: 6 November 2014 Published online: 18 November 2014

\section{References}

1. Cheung, WS, Ren, JL: On the existence of periodic solutions for $p$-Laplacian generalized Liénard equation. Nonlinear Anal. TMA 60, 65-75 (2005)

2. Ge, WG, Ren, JL: An extension of Mawhin's continuation theorem and its application to boundary value problems with a p-Laplacian. Nonlinear Anal. TMA 58, 477-488 (2004)

3. Meng, H, Long, F: Periodic solutions for a Liénard type $p$-Laplacian differential equation. J. Comput. Appl. Math. 224 696-701 (2009)

4. Meng, JX: Positive periodic solutions for Liénard type $p$-Laplacian equations. Electron. J. Differ. Equ. 2009,39 (2009)

5. Liu, WB: Existence and uniqueness of periodic solutions for a kind of Liénard type $p$-Laplacian equation. Nonlinear Anal. TMA 69, 724-729 (2008) 
6. Liu, WB, Liu, JY, Zhang, HX, Hu, ZG, Wu, YQ: Existence of periodic solutions for Liénard-type $p$-Laplacian systems with variable coefficients. Ann. Pol. Math. 109, 109-119 (2013)

7. Wang, Y, Dai, XZ, Xia, XX: On the existence of a unique periodic solution to a Liénard type $p$-Laplacian non-autonomous equation. Nonlinear Anal. TMA 71, 275-280 (2009)

8. Ding, $\mathrm{HS}$, Ye, GR, Long, W: Existence and uniqueness of periodic solutions for a class of nonlinear equations with p-Laplacian-like operators. Adv. Differ. Equ. 2010, Article ID 197263 (2010)

9. Wang, YY, Ge, WG: Periodic solutions for Duffing equations with a $p$-Laplacian-like operator. Comput. Math. Appl. 52, 1079-1088 (2006)

10. Wang, YY, Hou, CM, Ge, WG, Zhang, C: Existence of periodic solutions for second-order Duffing equations with p-Laplacian-like operator. Nonlinear Anal. 71, 2431-2440 (2009)

11. Manásevich, R, Mawhin, J: Periodic solutions for nonlinear systems with p-Laplacian-like operator. J. Differ. Equ. 145, 367-393 (1998)

doi:10.1186/s13661-014-0244-x

Cite this article as: Xin et al.: Existence and uniqueness of positive periodic solution for $\phi$-Laplacian Liénard equation. Boundary Value Problems 2014 2014:244

\section{Submit your manuscript to a SpringerOpen ${ }^{\odot}$ journal and benefit from:}

- Convenient online submission

- Rigorous peer review

Immediate publication on acceptance

- Open access: articles freely available online

- High visibility within the field

- Retaining the copyright to your article 